\title{
A qualitative study of Canada's experience with the implementation of electronic health information technology
}

\author{
Ronen Rozenblum PhD, Yeona Jang PhD, Eyal Zimlichman MD, Claudia Salzberg MS, Melissa Tamblyn MPA, \\ David Buckeridge MD PhD, Alan Forster MD MPH, David W. Bates MD MPH, Robyn Tamblyn PhD
}

\begin{abstract}
Background: In 2001, Canada Health Infoway unveiled a plan to implement a national system of interoperable electronic health records. This government-funded corporation introduced a novel model for interprovincial/territorial collaboration to establish core aspects of a national framework. Despite this $\$ 1.6$ billion initiative, Canada continues to lag behind other Western countries in adopting electronic health records. We conducted a study to identify the success of different aspects of the Canadian plan and ways to improve the adoption of electronic health records.
\end{abstract}

Methods: We used a case study approach to assess the 10-year history of Canada's e-health plan. National reports and documents were reviewed, and structured interviews were conducted with 29 key stakeholders representing national and provincial organizations responsible for establishing policy and strategic direction for health information technology. Using grounded theory, we analyzed tran- scripts of the interviews to identify themes and their relationships.

Results: Key stakeholders identified funding, national standards, patient registries and digital imaging as important achievements of the ehealth plan. Lack of an e-health policy, inadequate involvement of clinicians, failure to establish a business case for using electronic health records, a focus on national rather than regional interoperability, and inflexibility in approach were seen as barriers to adoption of the plan.

Interpretation: To accelerate adoption of electronic health records and timely return on investment, an e-health policy needs to be tightly aligned with the major strategic directions of health care reform. Adoption needs to be actively fostered through a bottom-up, clinicalneeds-first approach, a national policy for investment in electronic health records, and financial incentives based on patient outcomes that can be achieved with electronic health records.
Competing interests: None declared.

This article has been peer reviewed.

Correspondence to: Dr. Robyn Tamblyn, robyn.tamblyn@mcgill.ca

CMAJ 2011. DOI:10.1503 /cmaj.100856
$\mathrm{M}$ any countries have established national initiatives to implement information technologies to improve patient safety and the quality and efficiency of health care services, and Canada is no exception..$^{1-3}$ Many provinces have implemented health information technologies, such as electronic medical records in primary care in Alberta, population drug information in British Columbia and regional interoperable health networks in Sault Ste. Marie, Ontario, Building on these experiences, the federal government established Canada Health Infoway to accelerate the e-health agenda and to create a national system of interoperable electronic health records. ${ }^{4,5}$

Canada Health Infoway adopted a unique strategy to develop a national electronic health record system. Unlike other countries that leveraged local initiatives toward a national system to achieve high rates of adoption of electronic health records, ${ }^{1,6}$ Canada Health Infoway set out to establish a national infrastructure that would enable the exchange of health information from coast to coast. Core components of this plan included the establishment of a national architecture and standards; patient and provider registries that would enable information to be linked for the same patient; and the implementation of regional drug and laboratory repositories and digital imaging to improve efficiency in the exchange of clinical information in ambulatory care. Canada Health Infoway developed a change model that it used to guide the implementation of these ehealth initiatives at a national level (Box 1). ${ }^{4}$

Despite Canada Health Infoway's investment of almost $\$ 1.6$ billion toward more than 280 e-health projects in the past 10 years, ${ }^{7}$ Canada continues to lag behind other Western countries in adopting a system of electronic medical records. ${ }^{2,3,89}$ As of 2009 , only $36 \%$ of Canadian physicians were using electronic medical records, as compared with more than 90\% of physicians in Australia, the United Kingdom, New Zealand and the Netherlands 
(Figure 1). Given these international differences, we undertook this study to identify, from the perspective of policy and implementation strategy, the aspects of the Canadian e-health plan that succeeded, the aspects that were less successful and future directions to improve electronic health record adoption.

\section{Methods}

\section{Study design and population}

We used a case study approach ${ }^{10,11}$ to assess the effectiveness of the Canada e-health plan and to identify ways of increasing adoption of electronic health records in Canada. Such an approach was used by Hendy and colleagues to assess the implementation of a national program for health information technology in the United Kingdom. ${ }^{12,13}$

To conduct the case study, we reviewed Canada Health Infoway documents and interviewed representatives from national and provincial stakeholder groups. We purposively selected people who were responsible for leadership or policy or for information technology in their

Box 1: Components and highlights of Canada Health Infoway's change model used to guide the implementation of a national system of interoperable electronic health records ${ }^{4}$

\section{Leadership}

- Adopted a shared governance model with the provinces and territories to ensure continued collaboration and accountability.

- Implemented a co-investment model with the jurisdictions to leverage $\$ 1.6$ billion in federal funding.

\section{Approach}

- Created a single architecture for the country, based on a data-sharing approach aimed at linking local clinical systems with regional and provincial registries to create a longitudinal electronic health record that would be accessible to the clinician at the point of care. The architecture was used as a reference model for investment decisions.

- Used gated funding (the release of funds in accordance with performance benchmarks) to reduce financial risk and increase motivation for the jurisdictions to deliver projects on time and on budget.

- Linked project funding to the use of standards to support interoperability.

- Consolidated the efforts to establish national e-health standards into a single organization that involved all key stakeholders to accelerate adoption.

\section{Implementation}

- Established preferred pricing agreements with vendors; encouraged the use of commercial solutions and the replication of the same solutions across jurisdictions to help reduce risk and cost.

- Engaged professional associations as part of change management to accelerate adoption and use of e-health solutions by individual clinicians.

\section{Benefits}

- Developed a structured approach to measure the return on investment; benefits would be measured against the savings of $\$ 6$ to $\$ 7.6$ billion expected from improvements in patient safety and quality and effectiveness of health care delivery. organization from four stakeholder groups that are influential in the adoption of electronic health records: national and provincial agencies responsible for health information technology; quality/safety and public health agencies; health professional associations; and vendors of health information technology.

Because the provinces and territories are ultimately responsible for the implementation of electronic health records, we included leaders in e-health policy and implementation from three provinces that varied in the extent of implementation: Alberta, the most advanced; Ontario, the least advanced; and British Columbia, in the middle. ${ }^{14}$ Vendors and national and provincial leaders responsible for the implementation of health information technology were identified with the assistance of Canada Health Infoway. The chief executive officers of health professional associations and of quality/safety and public health agencies were asked to participate or identify the most appropriate leader of health information technology in their organization. Because physicians and pharmacists were the primary groups involved in the Canadian ehealth plan, we limited the health professional associations to these two groups.

We identified 32 potential representatives of national and provincial stakeholder groups, a similar number as that used in prior studies of the implementation of national e-health plans..$^{12,13,15}$

\section{Questionnaire development and administration}

Based on prior research,,$^{12,13,16-18}$ a semistructured questionnaire was constructed to assess factors from seven domains that might influence adoption of electronic health records: technical infrastructure and standards; interoperability; vendor engagement; financial incentives; facilitators and barriers to adoption; potential benefits in improved patient safety and effectiveness of health care delivery; and public health. The questionnaire solicited the participant's perceptions of the importance of each domain, facilitators and barriers to adoption, and future directions. A copy of the questionnaire is available in Appendix 1 (www.cmaj.ca/cgi/content /full/cmaj.100856/DC1).

For this study, the term "health information technology" was used to represent both electronic health records ${ }^{19}$ and electronic medical records. ${ }^{19}$

Potential participants were contacted by email and telephone. Those who consented to participate were sent a copy of the questionnaire before the scheduled interview. Three of us (R.R., E.Z., M.T.) conducted the interviews by telephone. They were recorded and transcribed with the consent of the informants. 


\section{Data abstraction}

We used the grounded-theory approach, ${ }^{20}$ a technique used in similar studies for analyzing qualitative data, ${ }^{12,13,15}$ to analyze the transcripts. The analysis was done with the aid of ATLAS.ti software (ATLAS.ti GmbH, Berlin, Germany). Transcripts were coded to extract common concepts. Through iterative readings and discussion of the transcripts by three of us (R.R., E.Z., C.S.), a list of coded concepts was developed to characterize the factors that influence adoption of health information technology. Codes were then grouped to delineate emerging themes and their relationships. We masked identifying information in excerpts from the interview transcripts to protect the confidentiality of the participants.

The McGill University Institutional Review Board approved the study design.

\section{Results}

Overall, 29 of the 32 selected representatives agreed to participate. Nine of the participants represented national or regional agencies responsible for health information technology, seven were from health professional groups, eight represented safety/quality and public health agencies, and five were from the vendor community.

Several aspects of Canada's e-health plan were viewed as successful (Box 2). Participants highlighted the benefits of having a comprehensive national approach to the standards for health information technology that set the foundation for interoperability in the future and that estab- lished a framework for collaboration across provinces and territories. A national organization was viewed as a way to help establish a coordinated approach to lobbying for political support. The release of funds in accordance with performance benchmarks (gated funding) was also a feature of the Canada Health Infoway plan that was seen as an enabler of provincial buy-in and commitment. In terms of clinical applications, digital imaging was viewed as the most successful, providing benefits for patients and reductions in cost.

Participants identified two main aspects of the e-health plan that were viewed as less successful. The first related to the absence of an e-health policy that would foster effective strategies for adoption by clinicians. The second related to the implementation of the national infrastructure for electronic health records.

Regarding the first aspect, participants commented that the direction and priorities for the ehealth plan needed to be aligned with the clinical and business needs of clinicians and the health care system through greater engagement of policy-makers (Box 3). Canada Health Infoway was seen as a funding agency, not a policy-setting body. The lack of a national policy or harmonized provincial policy to guide investment and adoption was seen as a problem.

Moreover, inadequate attention to clinicians, the key users of electronic health records, was viewed as a critical ingredient missing from the e-health vision (Box 3). To accelerate adoption, participants identified four key requirements:

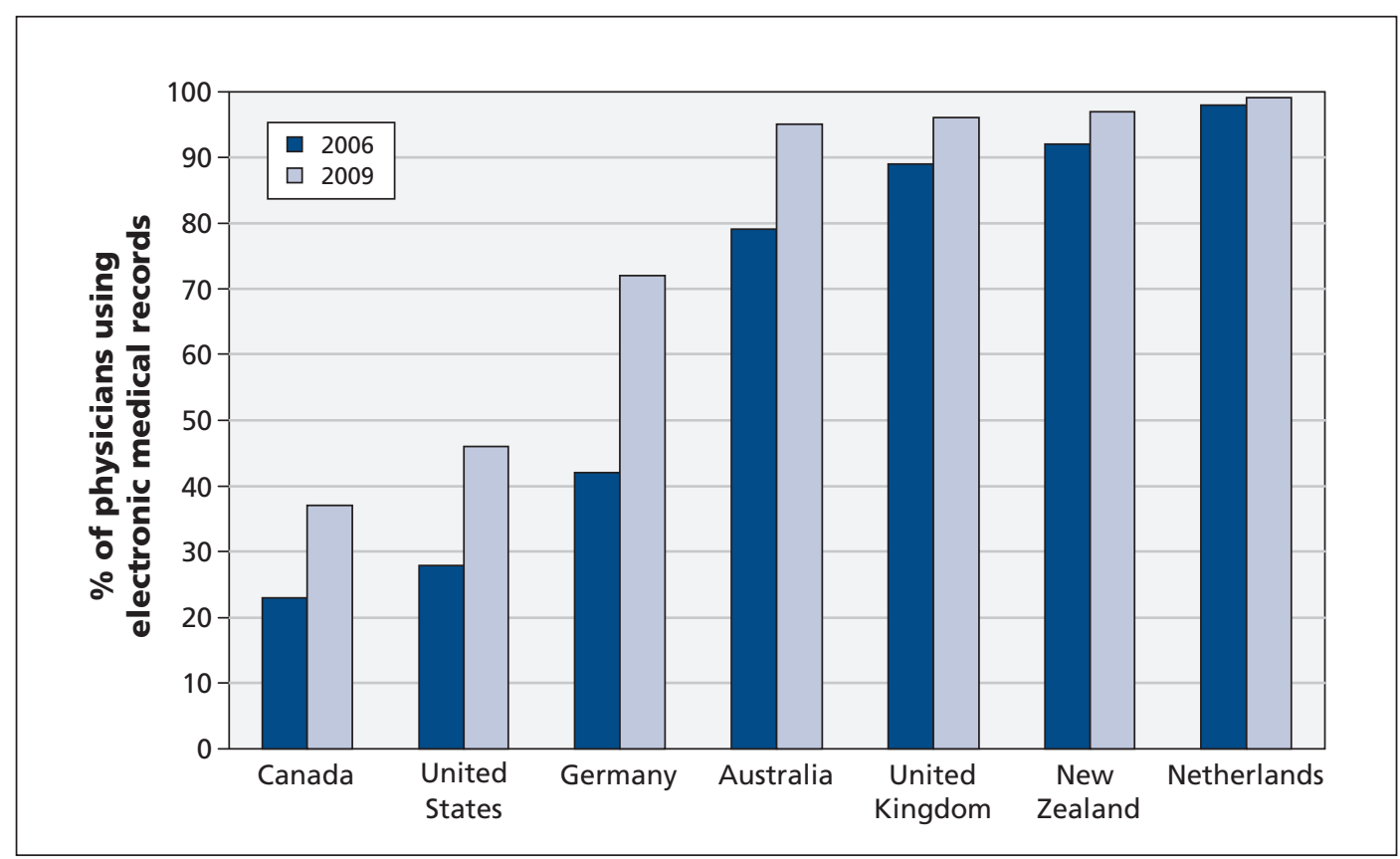

Figure 1: Proportion of physicians in seven countries who were using electronic health records in 2006 and 2009. . $^{2,3}$ 
meaningful engagement of clinicians; coordinated leadership and investment in electronic health records across the country in conjunction with provincial, professional and regulatory authorities; a revised payment model that would provide financial incentives based on patient outcomes that can be achieved with the use of electronic health records; and a focus on technology that would improve the value of health care.

Regarding the second aspect of the e-health plan viewed as being less successful, participants

Box 2: Aspects of Canada Health Infoway's e-health strategy that were viewed as successful by participants

- A comprehensive strategy that defined a national approach to the infrastructure and standards of health information technology (HIT) that will allow for interoperability across jurisdictions in the future

- "One of the better things Canada Health Infoway has done is set a common architecture for creating interoperable electronic health record, across all the jurisdictions ... and the different sectors of the healthcare system." - Health professional group, respondent 5

- "I think that one of [Canada Health Infoway's] biggest successes would probably be around their architecture work ... the understanding of what, where that sort of master architectural plan for the future will be, and how to get the pieces fitting into that architectural plan." - HIT agency, respondent 7

- A framework that coordinated and brought provincial HIT planning together, thereby promoting collaboration and sharing of ideas and strengthening provincial purchasing power

- " "[Canada Health Infoway] created a way to bring people together to start to talk about this common agenda." - Health professional group, respondent 1

- " "[Canada Health Infoway] definitely accelerated and provided some capabilities to reduce purchasing cost through collaborative bargaining through an organization that would have, essentially, a bigger stick than individual hospitals, purchasing equipment by themselves, so I think that they were able to push the cost down." Health professional group, respondent 2

- Successful lobbying for HIT, and acquisition of political and financial support

- "A second thing that [Canada Health Infoway] did was brought financial resources. One of the things that have always been a challenge is that even the really well-intentioned people could not get the budget and could not get the funding to go after it and to do it. So the Infoway money has certainly been an injection from that perspective." - HIT vendor, respondent 2

- "... [Canada Health Infoway] were smart enough to get and secure some very sizable financial resources to support the initiative." Health professional group, respondent 3

- "[Canada Health Infoway] can leverage the money so that they encourage the investment in health information technology." - HIT agency, respondent 1

- Digital imaging technology and provincial patient registries are the most successful HIT applications

- "I think the very fact that PACS systems [picture archiving and communication systems] got put in did create a certain amount of momentum for e-health." - Health professional group, respondent 4

- "The third thing would be facilitation by Canada Health Infoway of the client registry activity in various provinces and that includes Enterprise Master Patient Index. ... Canada Health Infoway really helps facilitate that on a national scale." - HIT agency, respondent 2 commented that stronger leadership was needed to implement national standards to address the challenges of migrating away from existing legacy systems (Box 4). Moreover, the stakeholders reported that the Canada Health Infoway blueprint needed to be less top-down, and more flexible and adaptive to accommodate changes in technology and feedback from implementation experiences. Although participants believed that national and even international standards were highly desirable, there was consensus that national interoperability was not a priority. Instead, they suggested that efforts be devoted to achieving effective regional interoperability both to support clinical adoption and to increase the speed of implementing systems to support the continuum of care. Moreover, there were concerns that Canada Health Infoway was unreasonably ambitious in its attempts to attain national interoperability when stakeholders considered regional interoperability to be more important, less expensive and easier to implement.

\section{Interpretation}

We identified important achievements of Canada Health Infoway's e-health plan. These successes included funding, national standards, patient registries and digital imaging. We also collected respondents' perspectives on why Canada may be lagging behind other countries in the adoption of electronic health records. Low rates of adoption were attributed to the lack of meaningful engagement of clinicians; poor alignment of the e-health plan and implementation strategy with the clinical and business needs of clinicians and the health care system; lack of flexibility in incorporating change; and a focus on national rather than regional interoperability.

A key finding that emerged was the absence of an e-health policy to align the investment in information technology with the priorities of the health care system and of health care providers in order to accelerate adoption and achieve early return on the investment. In non-health sectors, past failures and suboptimal rates of return from investment in information technology have been attributed to poor alignment of priorities with corporate objectives and strategies; ${ }^{21}$ this problem also appears to exist in the health sector. ${ }^{22,23}$ In most Western countries, health care systems face common challenges: improving patient safety, establishing better models for the management of chronic diseases, and engineering sustainability of the health care system in the face of escalating costs. ${ }^{24-26}$ In Canada, the vision of creating a national system of interoperable electronic health records that could be accessible coast to coast to 
deliver care has no immediate impact on any of these challenges. Indeed, most health care is rarely delivered outside provincial jurisdictions, which manage the health care system. ${ }^{27,28}$

The infrastructure established by Canada Health Infoway arguably provides an essential foundation for both local and interprovincial exchange. The foundation thereby offers synergies in investment and standardization in processes. Participants reported their belief in an architectural blueprint, national standards and registries as necessary components of the ehealth plan. However, the implementation of these aspects of the infrastructure alone are not sufficient to gain the improvements in patient safety and in quality and efficiency of health care services expected with health information technology. Institutions such as Kaiser Permanente $^{29}$ and the US Veterans Administration, ${ }^{30}$ which have established successful systems of electronic health records, have stressed the importance of also addressing the requirements of clinicians and patients. As highlighted in a recent editorial, ${ }^{31}$ Canada's e-health plan has not yet addressed issues around key components needed for clinicians to actually use electronic health records in the delivery of care. Indeed, key components such as problem lists, clinical notes and computerized decision-support were not in the ehealth investment plan.

An overly "top-down" approach and insufficient engagement of clinicians were aspects con-

Box 3: Future directions proposed by participants that were related to Canada's e-health policy and adoption of electronic health records

\section{E-health policy}

- Canada's e-health plan needs to be driven more by policy related to expected benefits for patients and providers than by technological solutions

- "I think policy should dictate or provide the parameters. Policy has a great significant impact on [health information technology (HIT)] infrastructure, simply because I think the business needs, or clinical needs, always need to drive the technology solution." - Regional HIT agency, respondent 3

- "When Canada Health Infoway got set up (and it was set up to implement, it was not a policy body), our federal health ministry at that time decided to downtool on the policy stuff. So, we have basically had a policy vacuum in this country for about eight years. We're doing more policy work out of [our organization] than anybody else. But, quite frankly, it should be national." - Health professional group, respondent 1

- "HIT is solving a legitimate business need: a hospital or a doctor doesn't put in a computer system because it pleases the government. They put in the computer system because they have a business need for it." - HIT vendor, respondent 2

- "What's the benefit to me as a physician to have an [electronic medical record]? ... Am I going to be able to give better care to my patients? Am I gonna be able to see more patients?" - HIT vendor, respondent no. 1 [in relation to questions asked by physicians]

- "At the end of the day, the success of these systems is whether or not they're essentially being used by clinicians. Therefore, if the clinician does not see value, if the clinician does not see how this can help him or her deliver care to their patients, these tools are simply not going to be used." - Health professional group, respondent 3

\section{Improving adoption of electronic health records}

- More meaningful engagement of clinicians is needed to ensure clinical utility to increase adoption

- "It's a fundamental belief of mine that, if clinicians are engaged early on in a project, then the user community will guide the development of systems in a way that ensures that those systems are clinically useful. And Infoway never really worked to create an engaged user community that would drive investment decisions." - HIT vendor, respondent 4

- "If you haven't got the end users involved and they are not driving adoption — it just isn't going to happen." - HIT vendor, respondent 3

- "I'll give you an example. In our jurisdiction, we have developed an entire solution for laboratory systems on which we've spent $\$ 120$ million but we have not properly involved all the end users. So, we are seven or eight years in, and this system is still not fully implemented." - HIT agency, respondent 4

- Investment in the promotion and implementation of electronic health records in collaboration with the regulatory and professional organizations is needed

- "I think one area that should have been funded in some way, earlier, is the electronic medical record strategy for each of the provinces. ... Even at this point in time, there's still a large piece of information that's missing from electronic health record strategies in every province." - HIT agency, respondent 7

- To increase patient benefits, payment models and incentives to promote adoption of electronic health records should be based on patient outcomes that can be achieved with electronic health records

- "I happen to have done some work for the New Zealand government and spent some time down there, and they're much more focused on the outcomes. So, uh... and the only way to get to those outcomes is to have an EMR [electronic medical record]. But, what they're paying the doctors for and what they're incenting them on is getting the outcomes." — HIT vendor, respondent 3

- " . ... in countries like the UK, there were incentives ... you know, targets, that if the physician was able to achieve those targets, there would be money coming back to support the physician or whatever, and obviously, the only way to track those targets or to identify the targets and track and report them, would be having a system." - Health professional group, respondent 3 
sidered by our participants, as well as by other Canadian critics, ${ }^{31-33}$ to have contributed to low adoption rates. Although a "top-down, technical, architecture-first" approach may eventually lead to the same outcome as a "bottom-up, clinicalneeds-first" approach would, the top-down approach was considered to be too slow, expensive and inefficient by some of the participants. Stakeholders involved in implementing the National Programme for IT (NPfIT), the national electronic health record system in the United Kingdom, expressed similar sentiments. ${ }^{12,13}$ Despite many early successes, NPfIT now faces serious challenges. ${ }^{13}$ Even though there is support for a national system in the United Kingdom, health care trusts, which are responsible for managing health care delivery, believe they have other more pressing priorities. ${ }^{13}$ Delays in

Box 4: Future directions proposed by participants that were related to the national infrastructure for electronic health records

- Strong leadership and structure is needed to engage stakeholders, build consensus, implement the e-health plan and get clinicians to adopt electronic health records

- "I think here is where you need very strong leadership in order to ensure that the provincial bodies are adopting lab standards, drug standards, etc., according to the same playbook. And, I think the resistance that we've had has obviously been the investment in legacy systems and the ability to transform those legacy systems into what is becoming an accepted norm around standards." - Health professional group, respondent 2

- Architecture and standards need to be adjusted to incorporate insights from implementation experiences and technology changes

- " ... the blueprint [Canada Health Infoway] developed, which is six or seven years old now, is too rigid. They developed something that wasn't designed to be flexible. And, as the system evolved, and as we developed insights on how [health information technology (HIT)] should be implemented, adopted and used, the blueprint was not able to adjust flexibly enough to allow for those changes." - Health professional group, respondent 2

- National interoperability is not a priority; interoperability needs to focus on the implementation of more rapid methods of supporting the continuum of care locally

- "[Provinces] have different priorities. So, here, you have a clash of all these architectures and standards and directions, and where the need, most of the need, at least $80 \%$ (and I've been told even higher) is really just local. And if we can solve the local problem, then we get a lot of value for the money, and then we can start to figure out how to hook the rest of these things together. I believe by using a local solution like that, we believe, you can solve about $80 \%$ of the problem for about $20 \%$ of the price, instead of trying to get the perfection and the centralized solutions that are going to be extremely difficult to do." - HIT agency, respondent 6

- "I think we are too worried about interoperability across the entire health care system. ... I would argue that health regions need to have interoperability first." - HIT vendor, respondent 4

- "Interoperability, based on leveraging existing investments, to me is a very achievable one, and very significant. The political paymasters, for example, still believe that the investments made in multiple disparate systems are wasted because systems cannot talk to one another. So, we have a major challenge here, in addition to the technology issues, we have major political issues." - HIT agency, respondent 5 achieving return on investment and benefits with information technology in health care can jeopardize the entire endeavour.

A relatively novel approach that addresses the challenge of return on investment tied to key clinical outcomes has been taken by the US Office of the National Coordinator for Health Information Technology. Using models such as those proposed by Bodenheimer and colleagues for the management of chronic diseases ${ }^{34}$ and by Bell and colleagues for improving drug safety, ${ }^{35}$ and using a scientifically robust investigation, the US Office of the National Coordinator for Health Information Technology has specified a list of requirements for clinically meaningful use, functions and features of electronic health records that will contribute to improved patient safety and better outcomes with management of chronic diseases. ${ }^{36}$ Coupled with appropriate financial incentives based on patient outcomes, it is anticipated that the $\$ 19$ billion invested in the US e-health plan has the potential to produce an earlier return on investment than the Canadian approach has. ${ }^{37}$

Three recommendations to improve adoption of electronic health records emerged from our study: investment in the implementation of electronic health records as a priority; more effective engagement of clinicians and other health care providers; and financial incentives based on patient outcomes that can be achieved with the use of electronic health records.

Canada Health Infoway's approach was to build the infrastructure and then let the provinces and territories implement applications that use this infrastructure. This plan stopped short of a coordinated national policy for adoption of electronic health records, such as the UK strategy ${ }^{6}$ that established a national framework for investment and business case development. In addition, Canada's e-health plan was not crafted to support the strengths of local innovation and development. The need to have technology that can be responsive and adaptive to local needs appears as a common thread in successful implementation strategies, both in health care and in other sectors. ${ }^{22,23,38,39}$

Engaged clinicians and responsive e-health systems allow early "quick wins" to be established. Clinicians can identify features that improve clinical efficiencies, such as the refilling of complex prescriptions, ${ }^{6,40}$ the retrieval of laboratory test results and graphing results over time, ${ }^{41}$ and the generation of patient lists (or reminders) for preventive care (i.e., a "bottom-up" approach). ${ }^{42}$

A successful strategy for achieving high adoption rates that a number of nations share involves two key initiatives: the expansion of proven deployments of prototypes of electronic 
health records, and the establishment of national policies for investment in electronic health records and for financial incentives tied to patient outcomes. $2.6,6,4,1,43,44$

Lastly, there was consensus among the participants that a process is needed to update the architecture and standards of the e-health plan on a continual, timely basis, and to provide guidelines and tools to manage this evolution. In addition, effective strategies for closing the gap between national standards and existing legacy systems were identified as a challenge in implementing the e-health system by our participants as well as by others in the United Kingdom ${ }^{12,13}$ and in Canada. ${ }^{32,33}$ In other business sectors outside of health care, heterogeneous technical environments are managed through various integration technologies and analytical approaches to guide the timing and extent of standardization. ${ }^{38,45}$ Effective use of strategies and best practices from other industries could help to reduce the risk of developing specialized, costly solutions that are unique to health care.

\section{Limitations}

The insights gained from the participants in our study provide salient recommendations for future directions. However, the themes that emerged may not be representative of all of the stakeholder groups represented. Also, we were unable to assess whether the participants' views varied across provinces or between stakeholder groups. Such differences may be relevant in understanding why some provinces have been more successful than others in implementing health information technology.

Our study focused on the policy and implementation framework established by senior leadership to enhance the adoption and use of electronic health records. Future research should focus on the expectations and experiences of health care professionals and patients, because their perspectives will inform and enrich the development of effective methods to enhance adoption.

\section{Conclusion}

Canada has implemented a national strategy for interoperable electronic health records by establishing a model for successful interprovincial collaboration on core aspects of a national framework. Looking forward, Canada needs to establish an e-health policy to guide the implementation of health information technologies to address the major strategic priorities of health care reform - improvements in patient safety, management of chronic diseases and sustainability of the health care system - and to promote the adoption of electronic health records and exchange of clinical data to address these challenges.

To achieve these objectives, policies are needed (a) to facilitate timely sharing of clinical information between health care providers in all settings, including community, hospital, long-term care facilities and home care; (b) to make personal health records and self-management tools accessible; (c) to support electronic communication between providers and members of interdisciplinary teams; (d) to establish incentives for the use of reminders for preventive care and for the use of comparative quality indicator assessment and reporting; (e) to facilitate the development of point-of-care, evidence-based clinical decisionsupport methods for personalized health care; (f) to enable reimbursement for e-visits; and (g) to reform the payment model to include financial reimbursement based on patient outcomes that can be achieved with the use of electronic health records. To foster innovation, policies are needed to support research and translation of successful regional initiatives (i.e., a "bottom-up" approach).

To increase adoption of electronic health records, strong clinical and administrative leadership will be needed, as will a cadre of clinicians trained in medical informatics to bridge the gap between information technology and health care. The creation of a chief provincial clinical information office is one approach that could be used to engage clinicians in the establishment of priorities for investment in health information technology, the development of clinically meaningful criteria for use of electronic records, and the construction of the business plan for computerization of primary care practices and community-based care.

\section{References}

1. Rich P. IT in general practice: a 10-country comparison. Future Pract 2006;21-23. Available: www.cma.ca/multimedia /CMA/Content_Images/Inside_cma/Future_Practice/English/2006 /November/IT_in_general_practice.pdf (accessed 2010 Dec. 13).

2. Schoen C, Osborn R, Doty MM, et al. A survey of primary care physicians in eleven countries, 2009: perspectives on care, costs, and experiences. Health Aff (Millwood) 2009;28:w1171-83.

3. Schoen C, Osborn R, Huynh PT, et al. On the front lines of care: primary care doctors' office systems, experiences, and views in seven countries. Health Aff (Millwood) 2006;25:w555-71.

4. Canada's health infostructure. Ottawa (ON): Health Canada; 2010. Available: www.hc-sc.gc.ca/hcs-sss/ehealth-esante /infostructure/index-eng.php (last accessed 2010 Dec. 13).

5. Health Canada. Canada e-health 2000 - from vision to action 2000. Ottawa (ON): Office of Health and the Information Highway, Health Canada; 2000. Available: www.hc-sc.gc.ca/hcs-sss /pubs/ehealth-esante/2001-vision-action-article/index-eng.php (last accessed 2010 Dec. 13).

6. Protti D, Wright G, Treweek S, et al. Primary care computing in England and Scotland: a comparison with Denmark. Inform Prim Care 2006;14:93-9.

7. Canada Health Infoway. Building a healthy legacy together. Toronto (ON): The Infoway; 2008. Available: www2.infowayinforoute.ca/Documents/ar/Annual_Report_2008-2009_en.pdf (last accessed 2010 Dec. 13).

8. Jha AK, Doolan D, Grandt D, et al. The use of health information technology in seven nations. Int J Med Inform 2008;77:848-54. 
9. Eggertson L. Canada lags US in adoption of e-prescribing. CMAJ 2009;180:E25-6.

10. Cavaye ALM. Case study research: a multi-faceted research approach for IS. Info Syst J 1996;6:227-42.

11. Tellis W. Application of a case study methodology. Qual Rep 1997;3.

12. Hendy J, Reeves BC, Fulop N, et al. Challenges to implementing the National Programme for Information Technology (NPfIT): a qualitative study. BMJ 2010;331:331-6.

13. Hendy J, Fulop N, Reeves BC, et al. Implementing the NHS information technology programme: qualitative study of progress in acute trusts. BMJ 2007;334:1360

14. Webster PC. Canada's electronic health records initiative stalled by federal funding freeze. CMAJ 2010;182:E247-8.

15. Poon EG, Blumenthal D, Jaggi T, et al. Overcoming barriers to adopting and implementing computerized physician order entry systems in U.S. hospitals. Health Aff (Millwood) 2004;23:184-90.

16. Miller RH, Sim I. Physicians' use of electronic medical records barriers and solutions. Health Aff (Millwood) 2004;23:116-26.

17. Valdes I, Kibbe DC, Tolleson G, et al. Barriers to proliferation of electronic medical records. Inform Prim Care 2004;12:3-9.

18. DesRoches CM, Campbell EG, Rao SR, et al. Electronic health records in ambulatory care - a national survey of physicians. N Engl J Med 2008;359:50-60.

19. Garets D, Davis D. Electronic medical records vs. electronic health records: Yes, there is a difference. Chicago (IL): HIMSS Analytics, LLC; 2006.

20. Strauss A, Corbin J. Basics of qualitative research: techniques and procedures for developing grounded theory. 2nd ed. Thousand Oaks (CA): Sage; 1998

21. Brynjolfsson E, Saunders A. Wired for innovation - how information technology is reshaping the economy. Cambridge (MA), London (UK): MIT Press; 2010.

22. Brender J, Ammenwerth E, Nykanen P, et al. Factors influencing success and failure of health informatics systems - a pilot Delphi study. Methods Inf Med 2006;45:125-36.

23. Nykänen P, Karimaa E. Success and failure factors in the regional health information system design process - results from a constructive evaluation study. Methods Inf Med 2006;45:85-9.

24. Yach D, Hawkes C, Gould CL, et al. The global burden of chronic diseases: overcoming impediments to prevention and control. JAMA 2004;291:2616-22.

25. Law S, Flood C, Gagnon D; Listening for Direction III partners Listening for direction III - national consultation on health services and policy issues, 2007-2010. Ottawa (ON): Canadian Health Services Research Foundation and Canadian Institutes of Health Research, Institute of Health Services and Policy Research; 2008.

26. Schoen C, Osborn R, How SK, et al. In chronic condition: experiences of patients with complex health care needs, in eight countries, 2008. Health Aff (Millwood) 2009;28:w1-16.

27. Pascal WJ. Reflections on an agenda: healthcare and information technology. Healthcare Inf Manag Commun Can 2009;32-4.

28. Mostashari F, Tripathi M, Kendall M. A tale of two large community electronic health record extension projects. Health Aff (Millwood) 2009;28:345-56

29. Chen C, Garrido T, Chock D, et al. The Kaiser Permanente Electronic Health Record: transforming and streamlining modalities of care. Health Aff (Millwood) 2009;28:323-33.

30. Evans DC, Nichol WP, Perlin JB. Effect of the implementation of an enterprise-wide Electronic Health Record on productivity in the Veterans Health Administration. Health Econ Policy Law 2006;1:163-9.

31. McGrail K, Law M, Hébert PC. No more dithering on e-health: let's keep patients safe instead. CMAJ 2010;182:535.

32. Webster PC. National electronic health records initiative remains muddled, auditors say. CMAJ 2010;182:E383-4.

33. Webster PC. National standards for electronic health records remain remote. CMAJ 2010;182:888-9.

34. Bodenheimer T, Wagner EH, Grumbach K. Improving primary care for patients with chronic illness: the chronic care model, Part 2. JAMA 2002;288:1909-14.

35. Bell DS, Cretin S, Marken RS, et al. A conceptual framework for evaluating outpatient electronic prescribing systems based on their functional capabilities. J Am Med Inform Assoc 2004;11:60-70.

36. Hogan SO, Kissam SM. Measuring meaningful use. Health Aff (Millwood) 2010;29:601-6.
37. Blumenthal D. Stimulating the adoption of health information technology. N Engl J Med 2009;360:1477-9.

38. Sirkin HL, Keenan P, Jackson A. The hard side of change management. Harv Bus Rev 2005;83:108-18, 158.

39. Scott JT, Rundall TG, Vogt TM, et al. Kaiser Permanente's experience of implementing an electronic medical record: a qualitative study. BMJ 2005;331:1313-6.

40. Tamblyn R, Huang A, Kawasumi Y, et al. The development and evaluation of an integrated electronic prescribing and drug management system for primary care. J Am Med Inform Assoc 2006; 13:148-59.

41. Denis P. Comparison of information technology in general practice in 10 countries. Healthc $Q$ 2007;5:107-16.

42. Shojania KG, Jennings A, Mayhew A, et al. The effects of onscreen, point of care computer reminders on processes and outcomes of care. Cochrane Database Syst Rev 2009;(3): CD001096.

43. Anderson GF, Frogner BK, Johns RA, et al. Health care spending and use of information technology in OECD countries. Health Aff (Millwood) 2006;25:819-31.

44. Webster PC. The pocketbook impact of electronic health records: Part 2. Fee-for-service billing is compatible with EHRs Disagreed. CMAJ 2010;182:753-4.

45. Shpilberg D, Berez S, Puryear R, et al. Avoiding the alignment trap in information technology. MIT Sloan Manage Rev 2007;49:50-9.

Affiliations: From the Division of General Medicine (Rozenblum, Zimlichman, Salzberg, Bates), Brigham and Women's Hospital, Harvard Medical School, Boston, Mass.; the Desautels Faculty of Management (Jang), McGill University, Montréal, Que.; Cancer Care Ontario (M. Tamblyn [at the time of the study]), Toronto, Ont.; McGill Clinical and Health Informatics (Buckeridge), McGill University, Montréal, Que.; the Clinical Epidemiology Program (Forster), Ottawa Hospital Research Institute, Ottawa, Ont.; and the Department of Medicine (R. Tamblyn), McGill University, Montréal, Que.

Contributors: All authors contributed to the study concept and design. Ronen Rozenblum, Eyal Zimlichman and Melissa Tamblyn conducted the interviews. Ronen Rozenblum, Eyal Zimlichman, Claudia Salzberg, Yeona Jang and Robyn Tamblyn contributed to the analysis and interpretation of the data. Ronen Rozenblum, Yeona Jang and Robyn Tamblyn drafted the manuscript. All of the authors critically revised the manuscript for important intellectual content and approved the final version submitted for publication.

Funding: This study was supported by the Commonwealth Fund (grant no. 20100011) and the Canadian Institutes of Health Research (grant no. ETG-92251).

Acknowledgements: The authors thank all of the people who gave their time to be interviewed for this study, including Richard Alvarez, Canada Health Infoway; Allen Ausford; Penny Ballem; Alan Brookstone, Cientis Technologies Inc.; Barry Burk, IBM Canada; Bill Conroy, Initiate Systems Inc.; Michael Decter; Mark Dermer, Central Ottawa Family Health Organization; Brian Forster and Wing-Si Luk, OntarioMD; Pamela C. Fralick, Canadian Healthcare Association; Vivek Goel; Mike Guerriere, Courtyard Group; Francis Lau; Sam Marafioti, Sunnybrook Hospital; Michael Martineau, Avenant Inc.; Bob Nakagawa, BC Ministry of Health Services; Tom Noseworthy, Calgary Institute for Population and Public Health; Bill Pascal, Canadian Medical Association; Jeff Poston, Canadian Pharmacists Association; Gregory J. Sherman, Office of Public Health Practice, Public Health Agency of Canada; Terry Sullivan, Cancer Care Ontario; John Swiniarski, College of Physicians and Surgeons of Alberta; and Michael Wolfson, University of Ottawa (formerly of Statistics Canada). 